\title{
Bjork-Shiley tricuspid valve endocarditis thirty years after implantation
}

\author{
Kasra Shaikhrezai ${ }^{1}$, Sanjeet Singh Avtaar Singh', Cristiano Spadaccio, Steven Hunter ${ }^{2}$ \\ ${ }^{1}$ Department of cardiothoracic surgery, Golden Jubilee National Hospital, Glasgow G81 4DY, UK. \\ ${ }^{2}$ Department of cardiothoracic surgery, Chesterman Wing, Northern General Hospital, Sheffield S5 7AU, UK.
}

Correspondence to: Dr. Kasra Shaikhrezai, Department of Cardiothoracic Surgery, Golden Jubilee National Hospital, Agamemnon Street, Glasgow G81 4DY, UK. E-mail: kasrash@gmail.com

How to cite this article: Shaikhrezai K, Singh SSA, Spadaccio C, Hunter S. Bjork-Shiley tricuspid valve endocarditis thirty years after implantation. Vessel Plus 2017;1:151-4.

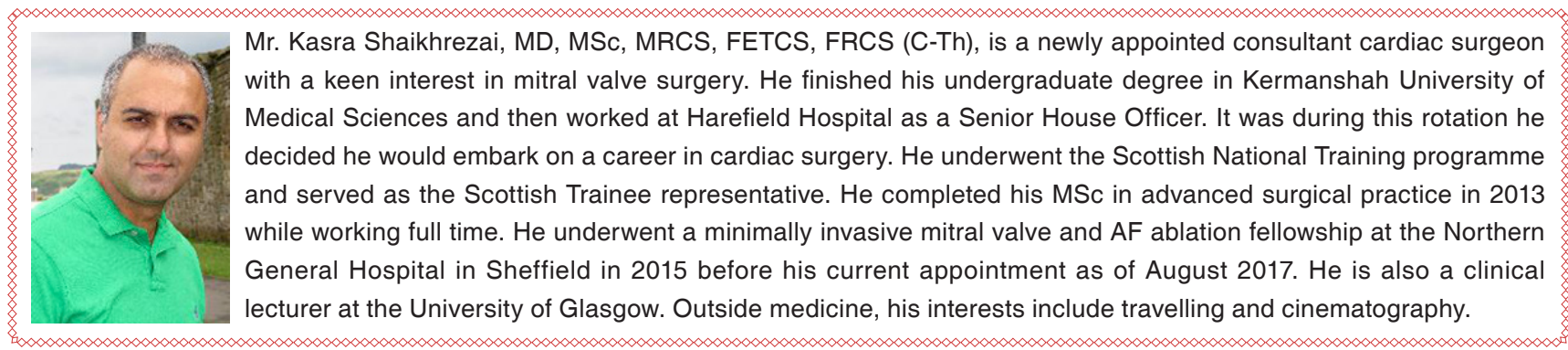

\section{Article history:}

Received: 4 Mar 2017

Accepted: 22 Aug 2017

Published: 26 Sep 2017

\section{Key words:}

Mechanical valve,

tricuspid valve stenosis,

endocarditis

\section{ABSTRACT}

The Bjork-Shiley valve has been in use since 1971. Its longevity has been well reported in the literature. The study report a case of the Bjork-Shiley valve implanted in a young man, who presents with bacterial endocarditis 30 years after implantation of the valve. Transthoracic echocardiography showed vegetations in the mechanical tricuspid valve, with positive blood cultures csonfirming the diagnosis. Artificial valves increase the risk of contracting endocarditis but this is the first report of a case of bacterial endocarditis occurring in a mechanical tricuspid valve replacement 30 years after the initial implantation.

\section{INTRODUCTION}

The choice of valve implantation is a complex decision that is usually made after consultation with the family and the patient. In the era of transcatheter valve insertions, the decision may start favouring the bioprosthetic valves. Recent updates in pericardial valves and anti- calcification techniques have also resulted in more durable bioprosthetic valves with outcomes surpassing 20 years expected, although this is yet to be seen in younger patients' due to the preference for a more durable mechanical valve given the potential longevity offered. Mechanical valves are also likelier to be used in the setting of mitral stenosis which almost invariably

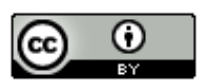

This is an open access article licensed under the terms of Creative Commons Attribution 4.0 International License (https://creativecommons.org/licenses/by/4.0/), which permits unrestricted use, distribution, and reproduction in any medium, as long as the original author is credited and the new creations are licensed under the identical terms.

For reprints contact: service@oaepublish.com

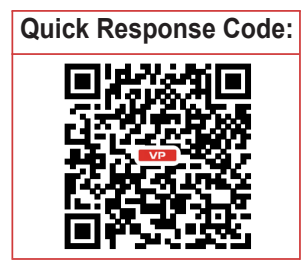


occurs alongside atrial fibrillation which is an indication for anticoagulation in itself. Point of care testing for anticoagulation efficiency with allied health professional led international normalised ratio clinics have been in favour of mechanical valves but the introduction of direct oral anti-coagulants (DOACs) for first line atrial fibrillation treatment has brought a paradigm shift favouring bioprosthetic valves. Tricuspid valve replacements however, are less common compared to the mitral valve, thereby lacking a consensus on the optimal choice of valve. As the right heart is a lower pressure system, the stasis of blood causing increase thrombogenicity may favour the use of tissue based valves. Artificial valves do predispose patients to an increased risk of bacterial endocarditis. This can be attributed to adherent surfaces of suture lines, turbulent flows and nidus for infections in microthrombi produced especially in mechanical valves.

We present a case report of a patient who presented 30 years after his first operation with bacterial endocarditis.

\section{CASE REPORT}

A 48-year-old Caucasian male presented to our institution with fever, shortness of breath and increasing fatigability. His past medical history included a previous tricuspid valve replacement with a Bjork-Shiley tilting disc valve in 1986 due to endocarditis from an unknown origin and severe tricuspid valve regurgitation.

As part of his follow-up, he attended annual surveillance echocardiography clinics. A possible pannus forming around the mechanical valve prosthesis was noted on his latest scan. This extensively reduced the effective orifice area. As he was well and asymptomatic, a plan was made to repeat the echocardiogram in 6 months' time. However, he became severely unwell following a urinary tract infection and required intravenous antibiotic therapy.

He was found collapsed and presented to the intensive care unit in our institute requiring mechanical ventilation. He had no pathognomonic signs of bacterial endocarditis such as splinter haemorrhages, Roth's spots, Osler's nodes and Janeway lesions. An urgent echocardiogram highlighted large prominent vegetations with severe tricuspid valve stenosis [Video 1]. Blood cultures were positive for Staphylococcus Aureus.

He had multiple episodes of non-sustained ventricular tachycardia. He later developed an acute kidney injury and the following a multidisciplinary team decision, he underwent an urgent redo-operation.

After right atriotomy, pannus and vegetation was observed on the mechanical valve were clearly visible [Figures 1 and 2]. The mechanical valve was explanted and replaced with a 31-mm bioprosthetic valve. His post-operative period was uneventful but for an episode of acute kidney injury which settled with intravenous fluids. He made a good recovery and was discharged on the 20th post-operative day. He was seen in the post-operative clinic after discharge and reports being well with no further complications.

\section{DISCUSSION}

Tricuspid valve endocarditis is a well recognised disease with a wide spectrum of pathologies which is not limited to intravenous drug abuse and can be caused even by monitoring lines. ${ }^{[1]}$ Up to $40 \%$ of prosthetic valve endocarditis is cause by Staphylococci infections. ${ }^{[2]}$ Artificial valve endocarditis is also more common in the atrioventricular valve owing to reduced flow velocities across the valves particularly in the right side of the heart. Pannus growth tends to occur in the tissue valve interface and tracks along the suture lines as seen in our patient. However, encroachment into
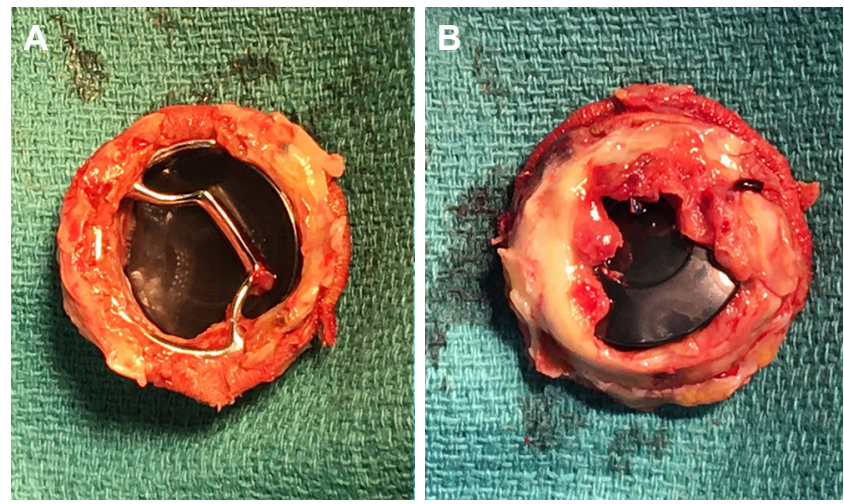

Figure 1: Pannus formation on atrial (A) and ventricular (B) surface of the valve; the patient remained asymptomatic and compliant with warfarinisation with no thromboemboli event during the 30 -year lifespan of the valve

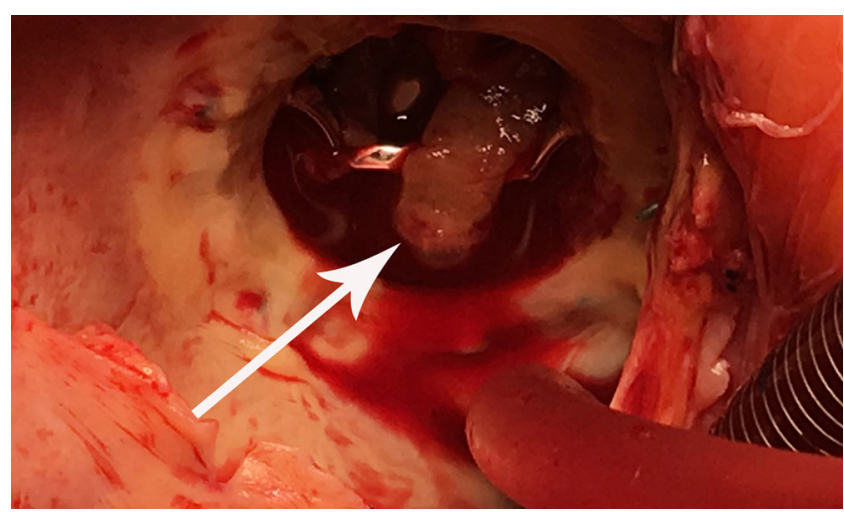

Figure 2: Vegetation (arrow) on atrial surface of the valve from surgeon's view; the endocarditis was caused by pyelonephritis with Staphylococcus Aureus 
the valve orifice is uncommon. Pannus formation was the causes mechanical valve obstruction in about $10 \%$ of valves. ${ }^{[3]}$

Implantation of prosthetic valve in tricuspid position has been debated frequently in the literature with a consensus on bioprosthesis favouring mechanical valve due to the increased occurrence of valve-related events, especially the composite of thrombosis, embolism, and bleeding high risk of thrombosis when a mechanical valve is implanted in tricuspid position. ${ }^{[4,5]}$ The management of thrombosis can be challenging and depending on patient clinical manifestation or degree of valvular obstruction the management can vary from observation to emergency operation. ${ }^{[6]}$

With the emergence of transcatheter technology, bioprosthetic valve implantation in the tricuspid position is an ideal alternative while future valve-in-valve implantation feasible in the event of valve failure. ${ }^{[7]}$ To our knowledge there is no report of mechanical valve implantation lasting more than 30 years in the tricuspid position. The abovementioned patient had excellent compliance with anticoagulation therapy, thus explaining his mechanical valve longevity without any episodes of thrombosis. It has been observed that non-compliance with coumadin plays a pivotal role in thrombosis and valve malfunction. ${ }^{[4]}$

Bjork-Shiley tilting disc valves had a good clinical profile following decades of implantation. However, they became obsolete following the invention of more innovative mechanical valves with better profiles facilitated by double tilting discs. In 1979, the convexoconcave design of the Bjork-Shiley valve came under scrutiny as it was prone to fractures in the outflow strut. This resulted in the food and drug administration withdrawing approval of the 1986, around the time our patient had his valve implanted. ${ }^{\left[{ }^{[3]}\right.}$

Despite advancements in valve design and refinement in surgical techniques, the type of valve implantation (mechanical versus bioprosthesis) remains a dilemma among surgeons in all 4 valves positions. Although, patient autonomy dictates that they be given priority to choose the type of valve, a surgeons input is of paramount importance. The evolving technology has influenced the guidelines with rapid amendments and new published editions. Newer generations of mechanical valves with better performance with regards to amplitude and duration of regional backflow velocities across the mechanical valve as the main culprit for thrombosis are currently available. ${ }^{\left[{ }^{[9]}\right.}$ DOACs may have a role in the mechanical valves of the future despite the findings of the recently published REALIGN trial. ${ }^{[10]}$ It may be a reality to have alternatives to coumadin therapy for mechanical valves in the near future.

\section{DECLARATIONS}

\section{Authors' contributions}

Writing manuscript, operating surgeon: K. Shaikhrezai Writing and reviewing manuscript: S.S.A. Singh

Reviewing manuscript: C. Spadaccio

Supervision and operating surgeon: S. Hunter

\section{Financial support and sponsorship}

None.

\section{Conflicts of interest}

There are no conflicts of interest.

\section{Patient consent}

Written consent was obtained from the patient preoperatively.

\section{Ethics approval}

Medical Photography was obtained with permission from the patient and the Local Clinical Governance Committee.

\section{REFERENCES}

1. Sundhu M, Mohapatra S, Arobelidze S, Gundelly P, Changarath Vijayan AK. Infective endocarditis in a patient with celiac disease after censtral venous catheter insertion. Cureus 2017;9:e1027.

2. Selton-Suty C, Célard M, Le Moing V, Doco-Lecompte T, Chirouze C, Iung B, Strady C, Revest M, Vandenesch F, Bouvet A, Delahaye F, Alla F, Duval X, Hoen B; AEPEI Study Group. Preeminence of staphylococcus aureus in infective endocarditis: a 1-year populationbased survey. Clin Infect Dis 2012;54:1230-9.

3. Deviri E, Sareli P, Wisenbaugh T, Cronje SL. Obstruction of mechanical heart valve prostheses: clinical aspects and surgical management. J Am Coll Cardiol 1991;17:646-50.

4. Yaminisharif A, Alemzadeh-Ansari MJ, Ahmadi SH. Prosthetic tricuspid valve thrombosis: three case reports and literature review. $J$ Tehran Heart Cent 2012;7:147-55.

5. Betancur-Gutiérrez A, Bayón-Fernández J, García-Rodríguez MÁ, García-Egido A, Garrote-Coloma C, Fernández-Vázquez F. Thrombosis of a mechanical tricuspid valve prosthesis resolved with fibrinolysis. Rev Esp Cardiol (Engl Ed) 2014;67:1064-6.

6. Joint Task Force on the Management of Valvular Heart Disease of the European Society of Cardiology (ESC); European Association for Cardio-Thoracic Surgery (EACTS); Vahanian A, Alfieri O, Andreotti F, Antunes MJ, Barón-Esquivias G, Baumgartner H, Borger MA, Carrel TP, De Bonis M, Evangelista A, Falk V, Iung B, Lancellotti P, Pierard L, Price S, Schäfers HJ, Schuler G, Stepinska J, Swedberg K, Takkenberg J, Von Oppell UO, Windecker S, Zamorano JL, Zembala $\mathrm{M}$. Guidelines on the management of valvular heart disease (version 
2012). Eur Heart J 2012;33:2451-96.

7. Panaich SS, Eleid MF. Tricuspid valve-in-valve implantation for failing bioprosthetic valves: an evolving standard of care. Ann Transl Med 2016;4:410.

8. Blackstone EH. Could it happen again? the björk-shiley convexoconcave heart valve story. Circulation 2005;111:2717-9.
9. Chaux A, Gray RJ, Stupka JC, Emken MR, Scotten LN, Siegel R. Anticoagulant independent mechanical heart valves: viable now or still a distant holy grail. Ann Transl Med 2016;4:525.

10. Shazly A, Afifi A. RE-ALIGN: first trial of novel oral anticoagulant in patients with mechanical heart valves - the search continues. Glob Cardiol Sci Pract 2014;2014:88-9. 